\title{
STUDY TO EVALUATE THE VITAMIN D SCENARIO IN AN INDIAN POPULATION
}

\section{Neurology}

Dr Firdushi Begum

Associate Professor, Deptt. Of Biochemistry, Gauhati Medical College \& Hospital, Assam, India.

\section{Dr Papori Borah*}

Assistant Professor, Deptt. Of Neurology, Assam Medical College, Assam,India. *Corresponding Author

\section{ABSTRACT}

Introduction : Till the $20^{\text {th }}$ century deficiency of vitamin $\mathrm{D}$ which is synthesized in the skin upon exposure to UVB light was largely unknown. But today vitamin D deficiency has taken an epidemic form and is linked with many disease conditions. Several studies have put forward a very high prevalence of vitamin D deficiency among Indians of all age groups.

Aims and objectives : To study the vitamin D status of people visiting a tertiary care centre in India.

Materials and Methods : This is a prospective observational study conducted in the Biochemistry section of Central Clinical Laboratory of Gauhati Medical College \& Hospital (GMCH). All the vitamin D reports generated in the laboratory for a period of 9 months were recorded and analysed to estimate the prevalence. Similar to other vitamin D studies, $20 \mathrm{ng} / \mathrm{ml}$ was taken as the cut-off for vitamin D deficiency, $30 \mathrm{ng} / \mathrm{ml}$ for insufficiency, and 30-100ng/ml as the normal vitamin D range.

Results and Observations : In this study Vitamin D data of 1000 patients admitted in GMCH was analysed. Of them females outnumbered males $(68.7 \%$ vs $31.3 \%)$. Of the 1000 vitamin D reports analysed $51.9 \%$ were found to be in the insufficient range, followed by $30.1 \%$ in the normal range. In $17.5 \%$ vitamin D levels were found to be deficient Vitamin D status was found to be lower in females as compared to males. $86.75 \%$ of females were either vitamin D deficient or insufficient and $71.88 \%$ of males were either deficient or insufficient.

Conclusion : In this study $17.5 \%$ of study subjects had vitamin D level $<20 \mathrm{ng} / \mathrm{ml}$, which may be considered as deficient, as per the Institute of Medicine(IOM) which considers a serum vitamin D value of $20 \mathrm{ng} / \mathrm{ml}$ as optimal. According to the U.S. Endocrine Society $30 \mathrm{ng} / \mathrm{ml}$ is optimal. Due to this variation the recommended daily intakes of this nutrient also vary.

\section{KEYWORDS}

Vitamin D, Deficiency, Insufficiency.

\section{INTRODUCTION :}

Vitamin D is a fat soluble steroid hormone that comes in two forms, vitamin D2 (ergocalciferol) and vitamin D3 (cholecalciferol).Vitamin D is synthesized in the skin upon exposure to UVB sunlight or we get it through our diet. It is hydoxylated in the liver and then in the kidney to form the active form i.e $1,25(\mathrm{OH})_{2}$ vitamin $\mathrm{D}$. Till the $20^{\text {th }}$ century Vitamin D deficiency was largely unknown. But today there is a large hue and cry regarding vitamin D deficiency taking an epidemic form just after diabetes mellitus and thyroid disease. Advanced techniques of vitamin D estimation and changing life style of the people because of which they are manly restricted indoors may be the two factors responsible for the spurt in vitamin D deficiency. Several studies have reported a very high prevalence of vitamin D deficiency in different populations across the world. Apart from low dietary intake, people suffering from hepatic, renal, dermatological disorders, alcoholics and inflammatory rheumatological conditions also have Vit D deficiency. In the late $18^{\text {th }}$ century vitamin $\mathrm{D}$ was first recognized as an essential dietary component in the prevention of rickets. But today it is linked with many disease conditions like cardiovascular disease, diabetes mellitus, cancer, tuberculosis , and autoimmune diseases among others, as has been brought forward by new research done in this field. India being in the tropical region receiving ample amounts of sunlight a high prevalence of vitamin D deficiency is highly unexpected. But several studies have put forward a very high prevalence of vit D deficiency among Indians of all age groups (1-3). Vitamin D deficient status can be corrected by augmenting its synthesis in the skin by exposing the skin to sunrays or by supplementation or fortification of food. But before taking any such steps we have to have a correct understanding of the status of vitamin D levels in the population concerned. There are no such studies which have studied the prevalence of vitamin D deficiency in this part of the Indian subcontinent. However it is seen that vitamin D is being prescribed haphazardly without individual assessment considering it to be widely prevalent. This study is a small step towards understanding the vitamin D scenario in this part of the country.

Aim : i) To study the vitamin D status of people visiting a tertiary care centre in India.

MATERIALS AND METHODS :

STUDYDESIGN :

Type of study: This study was planned as a prospective observational study.
Place of study : Biochemistry Section of Central Clinical Laboratory of Gauhati Medical College \& Hospital(GMCH). Gauhati Medical College \& Hospital is a tertiary level referral hospital and this study was aimed at studying the vitamin D status of patients and attendants visiting $\mathrm{GMCH}$.

Study Period : The study was conducted for a period of 9 months from July 2019 to March 2020.

Study protocol : All the vitamin D reports generated in the laboratory were recorded and analysed on a daily basis. The samples which were analysed were of patients visiting the hospital. The vitamin D reports of normal control population of a study on vitamin $\mathrm{D}$ conducted in the laboratory was also included in the study. Particulars regarding the patients name, age, sex, location and disease he/she was suffering from was collected from the requisition form sent to the laboratory along with the blood sample.

Vitamin D estimation : $1,25(\mathrm{OH})_{2}$ vitamin $\mathrm{D}$ is 1000 times lower than $25(\mathrm{OH})$ vitamin $\mathrm{D}$ and has a half life of 4 hours. Due to its half life of 23 weeks $25(\mathrm{OH})$ vitamin $\mathrm{D}$ is the metabolite that is the most reliable clinical indicator of vitamin D status. Also $25(\mathrm{OH})$ vitamin D levels are indicative of the body's storage levels of vitamin D and correlate well with the clinical symptoms of vitamin D deficiency. Serum 25(OH)D was estimated using the Vitros $25(\mathrm{OH}) \mathrm{D}$ total reagent pack on the Vitros 5600 Integrated System. A competitive immunoassay technique is used which involves the release of the $25(\mathrm{OH}) \mathrm{D}$ in the sample from the binding protein using a low ph denaturant and the subsequent competition of the free 25(OH)D with HRP labelled 25(OH)D reagent for the monoclonal anti-vitamin $\mathrm{D}$ bound to the wells. Calibration of the reagent was done every 28 days and one level of control was run with each batch of assay

Reference Range : Vitamin D $<20 \mathrm{ng} / \mathrm{ml} \quad$---- Deficient 20ng/ml-30ng/ml--- Insufficient $30 \mathrm{ng} / \mathrm{ml}-100 \mathrm{ng} / \mathrm{ml}$--- Normal

RESULTS \& OBSERVATIONS : Vitamin D status

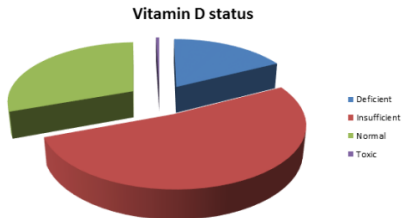

Fig 1 : Vitamin D status among the study participants. International Journal of Scientific Research 
Table 1 : Age wise distribution of vitamin $D$ status :

\begin{tabular}{|c|c|c|c|c|c|c|c|c|c|c|}
\hline \multirow{3}{*}{$\begin{array}{l}\text { Age } \\
\text { (Yrs) }\end{array}$} & \multirow{3}{*}{$\begin{array}{l}\text { Total } \\
\text { Num } \\
\text { bers }\end{array}$} & \multirow{3}{*}{$\begin{array}{l}\text { Vitamin D } \\
\text { mean } \pm \text { SD }\end{array}$} & \multicolumn{8}{|c|}{ Breakup of Vitamin-D status } \\
\hline & & & \multicolumn{2}{|c|}{ Deficient } & \multicolumn{2}{|c|}{ Insufficient } & \multicolumn{2}{|c|}{ Normal } & \multicolumn{2}{|c|}{ Toxic } \\
\hline & & & Nos & $\%$ & Nos & $\%$ & Nos & $\%$ & Nos & $\%$ \\
\hline Upto 15 & 69 & $35.03 \pm 0.54$ & 7 & 10.14 & 25 & 36.23 & 37 & 53.62 & 0 & 0 \\
\hline $15-30$ & 191 & $32.84 \pm 1.07$ & 46 & 24.08 & 92 & 48.17 & 53 & 27.75 & 0 & 0 \\
\hline $31-45$ & 297 & $28.86 \pm 1.55$ & 39 & 13.13 & 153 & 51.52 & 105 & 35.35 & 0 & 0 \\
\hline $46-60$ & 303 & $25.14 \pm 2.11$ & 54 & 17.82 & 172 & 56.77 & 74 & 24.42 & 3 & 0.99 \\
\hline$>60$ & 140 & $30.05 \pm 0.74$ & 29 & 20.7 & 77 & 55 & 32 & 22.86 & 2 & 1.43 \\
\hline
\end{tabular}

Table 2 : Genderwise distribution of Vitamin D status :

\begin{tabular}{|c|c|c|c|c|}
\hline \multirow{2}{*}{ Vitamin D } & \multicolumn{2}{|c|}{ Male } & \multicolumn{2}{c|}{ Female } \\
\cline { 2 - 5 } & Numbers & $\%$ & Numbers & $\%$ \\
\hline Deficient & 68 & 21.73 & 203 & 29.55 \\
\hline Insufficient & 157 & 50.16 & 393 & 57.21 \\
\hline Normal & 86 & 27.48 & 91 & 13.25 \\
\hline Toxic & 2 & 0.64 & 0 & 0.0 \\
\hline Total & 313 & 100 & 687 & 100 \\
\hline
\end{tabular}

\section{DISCUSSION :}

With the advent of new methods of Vit D estimation, low levels of vit D is increasingly being looked at as a causative factor of noncommunicable diseases. Various studies conducted therein to evaluate the Vit D status, have likewise revealed a wide prevalence of vitamin D deficiency. India being located in the tropical zone with ample amount of sunlight, its population should have been vitamin D sufficient but on the contrary studies have revealed a poor vitamin D status of the population at large(4). This present study is an extension of such prevalence studies and was aimed at getting an ideal picture of vitamin D status of the Indian population in this North-Eastern part of the country.

In this study 1000 Vitamin D data obtained from Central Laboratory of GMCH was analysed. Of them females outnumbered males $(68.7 \%$ vs $31.3 \%$ ). Most of the vitamin requisitions of female participants were of antenatal cases received from the Obstetric department. In the agewise break-up of the study participants, maximum were in the age group of 46-60 years, followed by $31-45$ years.

Of the 1000 vitamin D reports analysed $51.9 \%$ were found to be in the insufficient range, followed by $30.1 \%$ in the normal range. In $17.5 \%$ vitamin D levels were found to be deficient. Vitamin D reports of 5 patients were more than 100. Similar to other vitamin D studies, $20 \mathrm{ng} / \mathrm{ml}$ was taken as the cut-off for vitamin D deficiency, $30 \mathrm{ng} / \mathrm{ml}$ for insufficiency, and $30-100 \mathrm{ng} / \mathrm{ml}$ as the normal vitamin $\mathrm{D}$ range. These reference ranges are provided by the company supplying the kit. The prevalence of vitamin D deficiency ( moderate and severe) and sufficiency is quite similar to other studies. $(5,6)$ In a similar prevalence study conducted in a tertiary care hospital, $74.7 \%$ people were found to be either deficient or insufficient and $25.3 \%$ were vitamin D sufficient(7).

Vitamin D status was found to be lower in females as compared to males. $86.75 \%$ of females were either vitamin D deficient or insufficient and $71.88 \%$ of males were either deficient or insufficient. $57.21 \%$ of females were vitamin D insufficient as compared to $50.16 \%$ males. Previous studies of vitamin D status in women of both reproductive age group and post-menopausal women have reported a high percentage of vitamin D deficiency. Vitamin D deficiency status was found to be similar in rural and urban women(6,8). Female study participants were mainly of child bearing age in the age group of $15-$ $45 y e a r s$, and low sun exposure may be one of the factors responsible. Adequate sun exposure has been shown to have a positive correlation with vitamin D status. $(9,10)$.

In 5 patients the vitamin D reports were found to more than $100 \mathrm{ng} / \mathrm{ml}$. Follow-up of the patients when done revealed that they were on regular vitamin D supplements for several months, taking vitamin D to toxic levels.

During this time of Covid pandemic maintaining a normal Vitamin D level becomes all the more important. This is so because studies have shown that a daily or weekly vitamin D dose between $20 \mu \mathrm{g}$ and $50 \mu \mathrm{g}$ resulted in a significant reduction of respiratory tract infections.(11).

In this study vitamin D insufficiency was found more than deficient. Vitamin D insufficiency was defined as vitamin D level between 20-
$30 \mathrm{ng} / \mathrm{ml}$. Reference range for the Indian population is not defined as yet. In the absence of population based reference ranges categorizing them as insufficient will be unwarranted

A vitamin D status below 20ng/ml should be treated to achieve a minimum level of $30 \mathrm{ng} / \mathrm{ml}$. Values around $30 \mathrm{ng} / \mathrm{ml}$ are considered optimal with respect to skeletal activities(12).

\section{CONCLUSION :}

We know that the normal levels of different analytes vary in different age groups as also in different populations according to the location. Vitamin D is a very good example as its level in blood is influenced by diet and the environmental conditions of the region, it being synthesized in the skin following exposure to sunlight. There are no such studies which have brought forward the normal level of vitamin D in the Indian population though there are studies which have studied the prevalence of vitamin D deficiency in different Indian populations. All such studies have utilized the reference range provided by the reagent and analyzer manufacturer, which are again not based on the Indian population. This however results in bias in the interpretation of vitamin D status and thereby calculation of the prevalence.

The requirement of vitamin $\mathrm{D}$ in an individual and its healthy level is also a subject of debate. As per Institute of Medicine (IOM), a serum vitamin $\mathrm{D}$ value of $20 \mathrm{ng} / \mathrm{ml}$ is considered optimal in human adults whereas according to the U.S. Endocrine Society $30 \mathrm{ng} / \mathrm{ml}$ is optimal $(13,14)$. Due to this variation the recommended daily intakes of this nutrient also vary.

\section{Declarations :}

Acknowledgement :

None

\section{REFERENCES :}

. Harinarayan CV, Joshi SR. Vitamin D status in India -Its implications and Remedia Measures. J Assoc Physicians India 2009;57:40-48.

2. Marwaha RK, Sripathy G. Vitamin D and Bone mineral density of healthy schoo children in Northern India. Indian J Med Res 2008;127:239-44

3. Prentice A, Goldberg GR, Schoenmakers I. Vitamin D across the lifecycle: physiology and biomarkers. Am J Clin Nutr 2008;88(2):500S-506S.

4. Mithal A, Wahl DA, Bonjour JP, Burckhardt P, Dawson-Hughes B, Elsman JA, et al. IOF Committee of Scientific Advisors (CSA) Nutrition Working Group. Global Vitamin D status and determinants of hypovitaminosis D. Osteoporosis Int 2009;20:1807-20.

5. GR, Gupta A(2014). Fortification of foods with vitamin D in India. Nutrients;6:3601-23.

6. Harinarayan CV, Sachan A, Reddy PA, Satish KM, Prasad UV, Srivani P et al.Vitamin D status and bone mineral density in women of reproductive and postmenopausal age groups: a cross sectional study from South India. J Assoc Physicians India 2011;59:698-704

7. Mukul Arvindbhai. Joshi et al. A Study of Prevalence of Vitamin D deficiency in patients in tertiary care hospital; of an urbanized city Sch J App Med Sci2 2017:5(4A):1210-14

8. Sachan A, Gupta R, Das V, Agarwal A, Awasthi PK, Bhatia V et al. High Prevalence of Vitamin D deficiency among pregnant women and their newborns in northern India. Am J Clin Nutr; 81:1060-4

9. Holmes AM, Enoch BA, Taylor J, Jones ME. Occult rickets and osteomalacia amongst the Asian immigrant population. Quarterly Journal of Medicine 1973; 42(165):125-49.

10. Rucker D, Allan JA, Fick GH, Hanley DA. Vitamin D insufficiency in a population o healthy western Canadians. Canadian Medical Association Journal 2002; 166(12):1517 24

11. Martineau A.R., Jolliffe D.A., Hooper R.L. Vitamin D supplementation to prevent acute respiratory tract infections: systematic review and meta-analysis of individual participant data. BMJ. 2017;356:i6583

12. Vieth $\mathrm{R}$. Why the minimum desirable serum 25 -hydroxyvitamin $\mathrm{D}$ level should be $75 \mathrm{nmol} / \mathrm{L}(30 \mathrm{ng} / \mathrm{ml})$ Best Pract. Res. Clin. Endocrinol. Metab. 75 $\mathrm{nmol} / \mathrm{L}(30 \mathrm{ng} / \mathrm{ml})$ Best Pract. Res. C

13. Balvers MG, Brouwer-Brolsma EM, Endenburg S, de Groot LC, Kok FJ, Gunnewiek JK. Recommended intakes of vitamin D to optimise health, associated circulating 25 hydroxyvitamin D concentrations, and dosing regimens to treat deficiency: Workshop report and overview of current literature. J Nutr Sci. 2015;4:e23.doi: 10.1017/jns.2015.10. eCollection 2015.

14. Ross A, Manson J, Abrams S, Aloia J, Brannon P, Clinton S, et al. The 2011 report on dietary reference intakes for calcium and vitamin $\mathrm{D}$ from the Institute of Medicine: what dietary reference intakes for calcium and vitamin D from the Institute of Medicine: what
clinicians need to know. J Clin Endocrinol Metab. 2011;96(1):53-8.doi: 10.1210/jc.2010-2704. Epub 2010 Nov 29. 